\title{
Hyperthermia switches glucose depletion-induced necrosis to apoptosis in A549 lung adenocarcinoma cells
}

\author{
SONG IY HAN ${ }^{1}$, HONG-QUAN DUONG ${ }^{1}$, JEONG EUN CHOI ${ }^{1}$, TAE-BUM LEE ${ }^{1}$, CHO HEE KIM ${ }^{3}$, \\ SU YEON LEE ${ }^{3}$, HYUN MIN JEON ${ }^{3}$, SUNG-HEUI SHIN ${ }^{1}$, SUNG-CHUL LIM ${ }^{1,2}$ and HO SUNG KANG ${ }^{3}$ \\ ${ }^{1}$ Research Center for Resistant Cells, and ${ }^{2}$ Department of Pathology, College of Medicine, \\ Chosun University, Gwangju 501-759; ${ }^{3}$ Department of Molecular Biology, College of Natural Sciences, \\ and Research Institute of Genetic Engineering, Pusan National University, Pusan 609-735, Korea
}

Received November 26, 2007; Accepted January 22, 2008

\begin{abstract}
Both cellular and clinical studies have shown that hyperthermia is one of the most potent sensitizers for the action of ionizing radiation. Although hyperthermic improvement in clinical outcome is suggested to be linked to its ability to induce cell cycle arrest and apoptosis, and to activate the immune system and to cause increases in blood flow and tumor oxygenation, the mechanism behind this is still unclear. Previously, we demonstrated that glucose deprivation (GD), a common characteristic of the tumor microenvironment, induced necrosis, which is implicated in tumor progression and aggressiveness, through the production of reactive oxygen species (ROS) in A549 lung carcinoma cells. We examined the effects of heat shock on ROS production and necrosis in response to GD. Here we show that mild, but not harsh, heat shock prevented GD-induced necrosis and switched the cell death mode to apoptosis in A549 cells through the ERK1/2 pathway that could suppress GD-induced CuZnSOD release and ROS production. These results demonstrate that contrary to severe heat shock, mild heat shock has the ability to decrease oxidative stress in cells, thereby causing the cell death mode switch from tumor promoting necrosis to tumor suppressive apoptosis, which may contribute to its anti-neoplastic activities.
\end{abstract}

\section{Introduction}

Both cellular and clinical studies have shown that hyperthermia is one of the most potent sensitizers for the action of

Correspondence to: Dr Ho Sung Kang, Department of Molecular Biology, College of Natural Sciences, Pusan National University, Pusan 609-735, Korea

E-mail: hspkang@pusan.ac.kr

Dr Sung-Chul Lim, Research Center for Resistant Cells and Department of Pathology, College of Medicine, Chosun University, Gwangju 501-759, Korea

Key words: hyperthermia, necrosis, apoptosis, ROS, CuZnSOD, ERK1/2 ionizing radiation (1-3). Although hyperthermic improvement in clinical outcome is suggested to be linked to its ability to induce cell cycle arrest and apoptosis, to activate the immune system and to cause increases in blood flow and tumor oxygenation, the mechanism behind this is still unclear. Thus, the biological effects of hyerthermia have been studied extensively by many investigators.

Upon exposure to elevated temperatures, cells exhibit a conserved mechanism, the heat shock response. The most well characterized heat shock response is heat shock factor 1 (HSF1)-dependent induction of a highly conserved set of polypeptides termed the heat shock proteins (HSPs), which function as molecular chaperones and exert anti-apoptotic activities (4-6). Heat shock has been documented to prevent or promote cell viability and proliferation, depending on the strength and duration of applied heat stress as well as biological factors such as type of the cell line analyzed. In most cases, severe heat shock is thought to act as a proteotoxic stress which causes protein denaturation in cells and exerts a variety of anti-proliferative effects in mammalian cells. For instance, acute exposure to heat shock leads to a transient arrest of cells at mainly two cell cycle check points (G1/S and G2/M transitions), by inducing the p21 ${ }^{\mathrm{WAF} 1} \mathrm{CDK}$ inhibitor and other regulatory proteins (7-10). More severe heat shock induces the programmed cell death known as apoptosis (11-13). In contrast, mild heat shock is known to promote cell viability and proliferation. For example, feverranged hyperthermia facilitates interleukin 1-dependent $\mathrm{T}$ cell proliferation and activation (14). In addition, it stimulates cell proliferation as well as DNA synthesis in human bone marrow stromal cells and MG-63 cells in vitro (15). Moreover, mild heat shock induces the synthesis of cyclin D1, which plays a critical role(s) in the G1 progression of the cell cycle through multiple Ras signal pathways involving Rac1/ NADPH oxidase, extracellular regulated kinase (ERK), PI 3kinase (16). HSF1 activation and HSP expression in response to mild heat shock are regulated by a small GTPase Rac1 (17). Thus, mild heat shock is thought to evoke a cellular response(s) via a mechanism(s) different than the severe heat shock response. The mild heat shock response may be controlled by the unique signal cascade, which involves the Ras/Rac1 and ERK1/2 signal pathway, possibly activated 
by the thermal changes in the fluidity of membrane lipids (18-20). Heat shock has also been shown to regulate cellular redox state. Heat shock induces the production of reactive oxygen species (ROS) such as superoxide $\left(\mathrm{O}_{2}\right)$, hydrogen peroxide $\left(\mathrm{H}_{2} \mathrm{O}_{2}\right)$, and hydroxyl radical $\left(\mathrm{OH}^{-}\right)(12,21-24)$. The heat-mediated ROS is involved in heat shock-induced cytotoxicity and cell death (12); however, mild heat shock regulation of the cellular redox state has not been evaluated.

ROS elicits a wide spectrum of responses ranging from proliferation to growth arrest, to senescence and to cell death. Cellular damage by ROS is determined by the levels of defense antioxidant enzymes such as cytosolic CuZn superoxide dismutase (CuZnSOD), mitochondrial MnSOD, glutathione peroxidase $(\mathrm{GPx})$ and catalase $(25,26) . \mathrm{O}_{2}$ formed on both sides of the mitochondrial inner membranes is efficiently detoxified initially to $\mathrm{H}_{2} \mathrm{O}_{2}$ by cytosolic CuZnSOD and mitochondrial MnSOD and in turn, $\mathrm{H}_{2} \mathrm{O}_{2}$ is further converted to $\mathrm{H}_{2} \mathrm{O}$, with the help of GPx and catalase. Cells typically die by either apoptosis or necrosis upon severe oxidative stress. Unlike apoptosis that is a genetically controlled, programmed cell death which involves a proteolytic system consisting of caspases $(27,28)$, necrotic cell death is believed to result from injuries caused by an irreversible bioenergetic compromise regarded as accidental cell death and hence, is not programmed and uncontrollable (29-31). In the case of apoptosis, the cell content remains packed in the apoptotic bodies, and are removed by marcrophages; hence, inflammation does not occur. During necrosis, the cell membrane is ruptured, and the cytosolic constituents [e.g. a nuclear protein high mobility group box 1 (HMGB1)] are released into the extracellular spaces, causing a massive inflammatory response (29-32). In addition, necrosis and inflammation have been suggested as promoting tumor growth and angiogenesis through the tumor promoting activity of HMGB1 and by increasing the probability of protooncogenic mutation (33-38). The consequences of apoptosis and necrosis are quite different for a whole organism and it is crucial to determine how cells die by necrosis or apoptosis in response to oxidative stress, particularly with respect to the development of a tumor in an organism.

In solid tumors, necrosis is commonly found in the core region in response to oxygen and glucose depletion (OGD) due to insufficient vascularization $(39,40)$ and OGD-induced necrotic cell death, which may contribute to tumor growth and aggressiveness through a tumor-promoting cytokine, HMGB1. Previously, we demonstrated GD-induced necrosis through the production of ROS in A549 lung carcinoma cells and that protein kinase C-dependent ERK $1 / 2$ activation switched GD-induced necrosis to apoptosis through the inhibition of ROS production, possibly by inducing MnSOD expression and the prevention of GD-induced down-regulation of CuZnSOD (41). Futhermore, we showed that CuZnSOD is released into the extracellular space in an active form upon $\mathrm{GD}$, thereby accelerating ROS (possibly $\mathrm{O}_{2}{ }^{\prime}$ ) damage and facilitating necrotic cell death (42). We examined the effects of heat shock on ROS production and necrosis in response to GD and found that mild heat shock switched GD-induced necrosis to apoptosis through the ERK1/2 pathway that could prevent GD-induced CuZnSOD release and ROS production. In contrast, harsh heat stress enhanced GD-induced necrosis.
Thus, we suggest that heat shock may accelerate or suppress GD-induced necrosis depending on the strength of the applied heat stress and that necrosis-to-apoptosis switch activity of mild heat shock may contribute to its tumor-suppressive activities.

\section{Materials and methods}

Cell culture and drug treatment. Human lung adenocarcinoma cell line A549 cells were obtained from American Type Culture Collection and grown in RPMI-1640 media (Gibco-BRL) supplemented with $10 \%$ (v/v) heat-inactivated fetal bovine serum (FBS, Gibco-BRL) and $1 \%$ penicillinstreptomycin (PS, Gibco-BRL) in a $37^{\circ} \mathrm{C}$ humidified incubator with $5 \% \mathrm{CO}_{2}$. For glucose deprivation, cells were gently rinsed twice with glucose-free RPMI-1640 and incubated in GD medium [glucose-free RPMI-1640 medium (Gibco-BRL), containing $10 \%$ dialyzed and heat-inactivated FBS and $1 \%$ PS]. For heat shock treatment, A549 cells were heat-shocked at $39-45^{\circ} \mathrm{C}$ for the indicated times and then allowed to recover at $37^{\circ} \mathrm{C}$. To examine the effects of inhibitors, A549 cells were pre-treated with chemicals including U0126 $(10 \mu \mathrm{M})$, PD98059 $(30 \mu \mathrm{M})$, disulfiram $(1 \mu \mathrm{M})$, N-acetyl-Lcysteine (NAC, $10 \mathrm{mM})$, tiron $(5 \mathrm{mM})$, catalase $(1,000 \mathrm{U} / \mathrm{ml})$, or sodium formate $(50 \mathrm{mM}$, Sigma) for $1 \mathrm{~h}$, followed by heat shock or GD treatment in the presence of inhibitors.

RNA interference of CUZnSOD. pSUPER-CuZnSOD shRNA was generated from annealed oligonucleotides (5'-GATC CCCㄷGCTGACAAAGATGGTGTTTCAAGA $\underline{\text { ACACC }}$ ATCTTTGTCAGCAGTTTTTA-3' and 5'-AGCTTAAAAA CTGCTGACAAAGATGGTGTTCTCTTGAA ACA CCATCTTTGTCAGCAGGGG-3') inserted into the HindIII and $B g$ III sites of pSUPER-retro vector (OligoEngine, Seattle, WA, USA) with the 19-nucleotide human $C u Z n S O D$ target sequence underlined which was designed specifically for $C u Z n S O D$ by BLAST search against the human genome [(266-284 nucleotide, Genbank (accession no. CR541742)]. For transient shRNA transfection, the magnetofection method was used according to the manufacturer's procedures (Chemicell GmbH, Germany). Briefly, before addition of vector preparations to A549 cells in 12-well plates, the cells were washed once with FBS- and antibiotics-free DMEM medium. Transfection mixtures were provided as $1 \mu \mathrm{g}$ pSUPER-CuZnSOD shRNA plus $4 \mu 1$ PolyMAG reagent in a volume of $250 \mu \mathrm{l}$ DMEM during transfection. For magnetofection, the culture plates were positioned on magnetic plates for $15 \mathrm{~min}$ in a $37^{\circ} \mathrm{C} \mathrm{CO}_{2}$ incubator. The transfection mixture was then removed and continued for cultivation in $2 \mathrm{ml}$ of complete medium for $36 \mathrm{~h}$, after which cells were subjected to GD.

Western blot analysis, enzyme activity assay and transcription-polymerase chain reaction (RT-PCR). Western blotting with antibodies to PARP (Santa Cruz), active caspase-3, active caspase-9 (Cell Signaling), CuZnSOD, MnSOD, catalase, actin (Santa Cruz), $\alpha$-tubulin (Biogenex), ß-tubulin (Sigma), ERK1/2, p-ERK1/2 (Cell Signaling), and HMGB1 (BD PharMingen) were performed as described previously $(41,42)$. SOD activity was monitored by nitroblue 
tetrazolium negative staining after native gel electrophoresis on $7 \%$ polyacrylamide gels, as described previously $(41,42)$. The lower band was pre-confirmed as CuZnSOD and upper band as MnSOD in the gel by which incubation with $5 \mathrm{mM}$ sodium cyanide showed only the upper band. Catalase activity in non-denaturing $7 \%$ polyacrylamide gels was also monitored as described previously $(41,42)$. For reverse transcription-polymerase chain reaction (RT-PCR), total RNA's were prepared from cells and the first-strand cDNA's were subsequently amplified with primers for MnSOD, $\mathrm{CuZnSOD}$, catalase and $\mathrm{B}$-actin.

Measurement of intracellular ROS. To determine the production of intracellular $\mathrm{H}_{2} \mathrm{O}_{2}$ and $\mathrm{O}_{2}$, cells were plated in 48 -well plates (at $2 \times 10^{4}$ cells/well) or on cover-glass for a fluorocount measurement or fluorescence microscopic detection, respectively. After the GD treatment, cells were incubated in a $37^{\circ} \mathrm{C}, \mathrm{CO}_{2}$ incubator loaded with 2, 7-dichlorofluorescin diacetate (DCFH-DA, Molecular Probes, $50 \mu \mathrm{M}$ ) or dihydroethidium (HE, Molecular Probes, $10 \mu \mathrm{M}$ ) for the last $30 \mathrm{~min}$ of the indicated incubation times. Fluorescence measurements were obtained with a Fluorocount plate reader (MQX200) with excitation at $488 \mathrm{~nm}$ and emission at $530 \mathrm{~nm}$ for DCFH-DA, and excitation at $515 \mathrm{~nm}$ and emission at $610 \mathrm{~nm}$ for HE. Intacellular ROS was also determined using a fluorescence microscope (DM5000, Leica, Germany) using an L5 filter cube (excitation: BP 440-520 nm, emission: BP 497-557 nm) and a TX2 filter cube (excitation: BP 520-600 nm, emission: BP 570-720 nm) for DCFH-DA and $\mathrm{HE}$, respectively.

Hoechst 33342 (HO)/propidium iodide (PI). Cells were incubated either with $1 \mu \mathrm{g} / \mathrm{ml} \mathrm{HO}$ and $5 \mu \mathrm{g} / \mathrm{ml} \mathrm{PI}$ at $37^{\circ} \mathrm{C}$, $5 \% \mathrm{CO}_{2}$ for $15 \mathrm{~min}$ in the dark. Both floating and attached cells were collected by centrifugation and trypsinization of the medium. The pooled cell pellets were immediately fixed in $3.7 \%$ formaldehyde, washed with phosphate-buffered saline (PBS), which was resuspended with a fraction of the suspension centrifuged in a cytospinner (Thermo Shandon, Shandon Inc.). The slides were then washed in PBS to remove excessive dye, air dried, mounted in FluroGard Antifade, and examined by fluorescence microscopy 340/425 nm (HO), and 580/630 nm (PI) (Olympus, FV1000).

HMGB1 release assay. Cell culture medium was collected at the indicated time points whereas the cells and debris were removed by centrifugation at 2,400 x g for $20 \mathrm{~min}$ at $4^{\circ} \mathrm{C}$. The supernatant was first filtered through Centricon YM-100 (Millipore) to clear the samples from cell debris and macromolecular complexes formed during clotting. Following this step, samples were concentrated to 15-fold with Centricon YM-30 and analyzed by Western blotting with antibody to polyclonal anti-HMGB1 antibodies (BD PharMingen). HMGB1 was identified as a $29-\mathrm{kDa}$ protein.

Lactate dehydrogenase ( $L D H$ ) assay. Cells were plated at a concentration of $1 \times 10^{4}$ per well in 96-well plates 1 day before heat shock treatment. After 2.5 -h incubation at $41^{\circ} \mathrm{C}$ for heat shock or $37^{\circ} \mathrm{C}$ for control, medium was replaced by GD medium and incubated for another 12 or $18 \mathrm{~h}$ and the released LDH was determined using cytotoxicity assay kit II (Bio Vision, CA, USA) as manufacturer's protocol. Briefly, the plates were centrifuged at $600 \mathrm{x}$ g for $10 \mathrm{~min}$, and then the cell-free supernatant was transferred to 96-well plate, mixed with LDH Reaction Mix, incubated for $30 \mathrm{~min}$ and measured the absorbance at $450 \mathrm{~nm}$. The percentage of specific LDH release was calculated by the following formula: $\%$ cytotoxicity $=[($ experimental $\mathrm{LDH}$ release $)-($ spontaneous LDH release by effector and target)/(maximum LDH release) (spontaneous LDH release)] x 100. The spontaneous release of $\mathrm{LDH}$ activity from control cells was $<2 \%$ of the maximal release of LDH activity, which was determined from the complete lysis by adding lysis buffer. All assays were performed in triplicate.

\section{Results}

Mild heat shock switches GD-induced necrosis to apoptosis, whereas harsh heat shock enhances necrosis. As demonstrated previously $(41,42)$, GD induced necrosis in A549 cells as determined by the HO/PI staining method. This double staining method involves the use of DNA-binding dyes (HO), which are known to cross the plasma membrane of all cells, whether they are damaged or not, causing a blue fluorescence of their nuclei and PI, which only penetrate cells with damaged membranes and lead to nuclear fluorescence. Thus, intact blue nuclei, condensed/fragmented blue nuclei, condensed/fragmented pink nuclei, and intact pink nuclei were considered viable, early apoptotic, late apoptotic (secondary necrotic), and necrotic cells, respectively. GD increased the population of cells which had intact pink nuclei (Fig. 1A). We examined the effects of heat shock on GD-induced necrosis. As shown in Fig. $1 \mathrm{~A}$ and $\mathrm{B}$, mild heat shock $\left(41^{\circ} \mathrm{C}\right.$ for $2.5 \mathrm{~h}$ ) markedly prevented GD-induced necrosis and switched the cell death mode to apoptosis, whereas harsh heat shock $\left(43^{\circ} \mathrm{C}\right.$ for $\left.2.5 \mathrm{~h}\right)$ slightly enhanced GD-induced necrosis. Mild or harsh heat shock alone did not affect the cell viability (Fig. 1A). Mild heat shock significantly decreased the population of PI-positive cells and increased cells having condensed/fragmented blue nuclei. A maximal cell death mode switch effect of mild heat shock was observed with heat shock at $41^{\circ} \mathrm{C}$ for $2.5-3 \mathrm{~h}$ (Fig. 1B). GD-induced HMGB 1 release was also suppressed by treatment of the mild heat shock (Fig. 1C). Mild heat-potentiated GD-induced apoptosis was mediated by caspase-9 (activated via mitochondrial death pathway) and caspase-3 (Fig. 1D), but not by caspase-8 (activated via the extrinsic death receptor pathway; data not shown) and a p85 fragment of PARP (a welldocumented caspase-3 substrate), was detected when mild heat shock-treated cells were exposed to GD (Fig. 1D). A broad caspase inhibitor (z-VAD-fmk) completely suppressed mild heat-potentiated GD-induced apoptosis (Fig. 1E).

Mild heat shock suppresses GD-induced ROS production through inhibition of GD-induced $C u Z n S O D$ release. ROS play a critical role(s) in the determination of the GD-induced cell death mode (41-43). GD significantly enhanced the production of intracellular $\mathrm{H}_{2} \mathrm{O}_{2}$ and $\mathrm{O}_{2}$ (Fig. 3). The source of ROS production has been shown to be mitochondria (41-43). We examined whether the effects of heat shock 
A
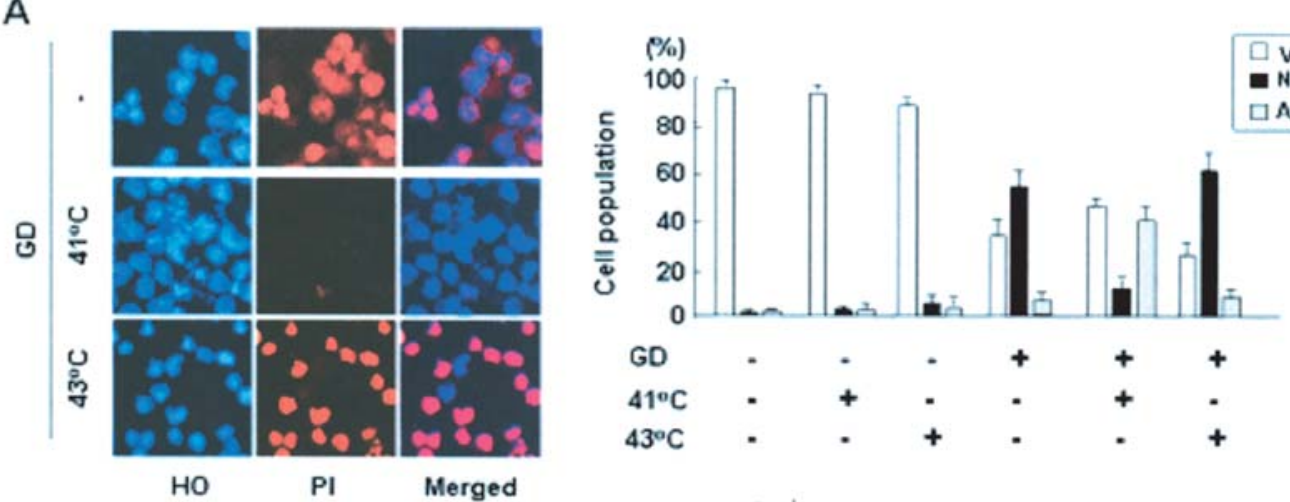

B
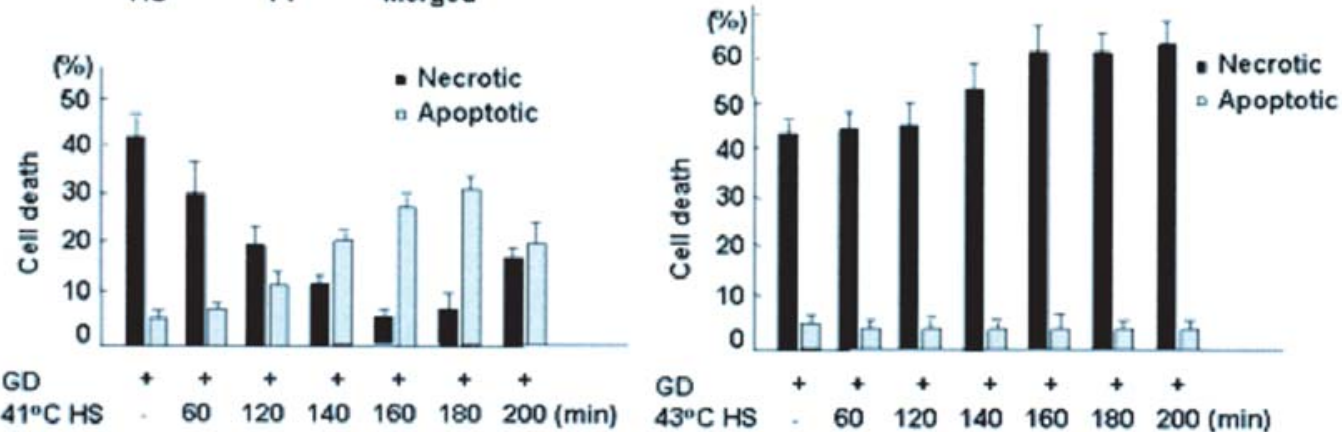

C

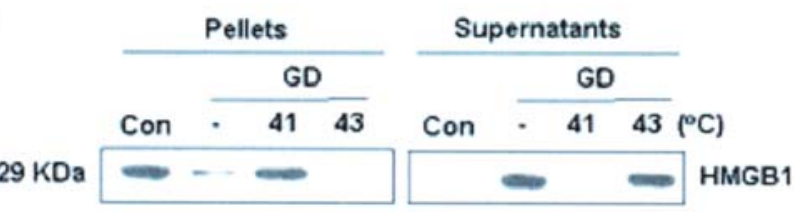

D

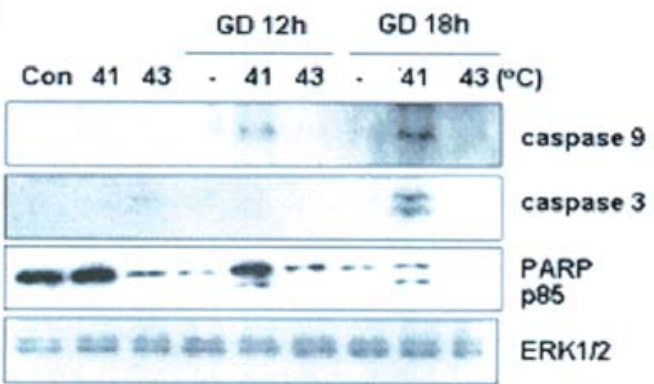

$E$

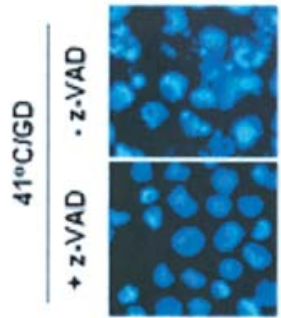

$\mathrm{HO}$

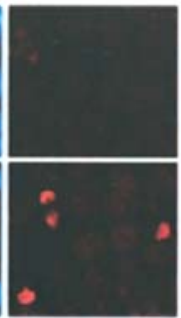

PI

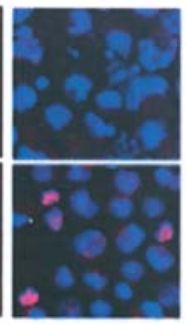

Merged

Figure 1. Mild heat shock switches GD-induced necrosis to apoptosis, whereas harsh heat shock enhances necrosis. (A) A549 cells were pre-treated with heat shock at $41^{\circ} \mathrm{C}$ or $43^{\circ} \mathrm{C}$ for $2.5 \mathrm{~h}$ and then exposed to GD medium at $37^{\circ} \mathrm{C}$ for $18 \mathrm{~h}$. The cells were stained with $\mathrm{HO} / \mathrm{PI}$ and observed under a fluorescence microscope (DM5000, Leica, left panel). Apoptotic and necrotic cells were scored (right panel). In these analyses, we observed 500-800 cells in each group. Data are expressed as the means \pm SEM from three independent experiments. (B) A549 cells were pre-treated with heat shock at $41^{\circ} \mathrm{C}$ and $43^{\circ} \mathrm{C}$ for the indicated times and then exposed to GD medium for $18 \mathrm{~h}$. The cells were stained with HO/PI and apoptotic and necrotic cells were scored. In these analyses, 500-800 cells in each group were counted. Data are expressed as the means \pm SEM from three independent experiments. (C) A549 cells were pre-treated with heat shock at $41^{\circ} \mathrm{C}$ or $43^{\circ} \mathrm{C}$ for $2.5 \mathrm{~h}$ and exposed to GD medium for $18 \mathrm{~h}$ and both the medium bathing the cells (supernatants) and the cells (pellets) were prepared according to Materials and methods and analyzed by Western blotting using antibodies for HMGB1. (D) A549 cells were pre-treated with heat shock at $41^{\circ} \mathrm{C}$ for $2.5 \mathrm{~h}$ and exposed to GD medium for the indicated times. The cellular proteins were analyzed by SDS-PAGE and Western blotting with antibodies to active caspase-9, active caspase-3, PARP and ERK1/2. (E) A549 cells were pre-treated with $25 \mu \mathrm{M} \mathrm{z}-\mathrm{VAD}$-fmk for $1 \mathrm{~h}$ and incubated at $41^{\circ} \mathrm{C}$ for $2.5 \mathrm{~h}$ and then exposed to GD medium in the presence of $25 \mu \mathrm{M} \mathrm{z}$-VAD-fmk $18 \mathrm{~h}$. The cells were stained with HO/PI and observed under a fluorescence microscope.

are linked to the regulation of GD-induced ROS production. As shown in Fig. 2A, mild heat shock lowered production of intracellular $\mathrm{H}_{2} \mathrm{O}_{2}$ and $\mathrm{O}_{2}$ in response to GD. Previously, we demonstrated that $\mathrm{CuZnSOD}$ is released into the extracellular space in an active form upon GD, thereby accelerating ROS (possibly $\mathrm{O}_{2}$ ) damage and facilitating necrotic cell death (42). We show that pre-treatment of mild, but not harsh, heat shock significantly suppressed GD-induced CuZnSOD release into extracellular space without affecting protein levels and activities of MnSOD and catalase (Fig. 2B and D). 
A $\mathrm{O}_{2}$
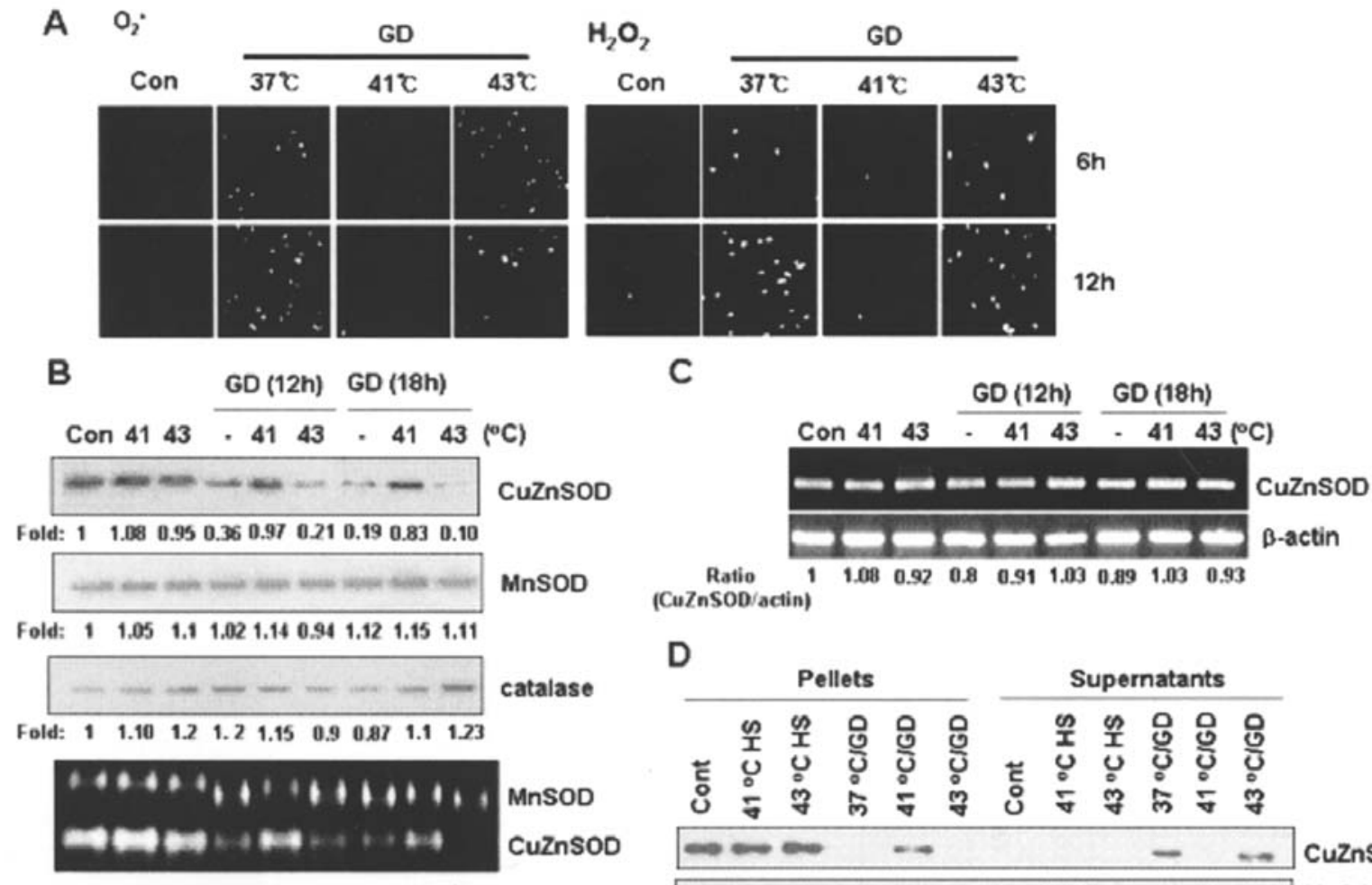

D
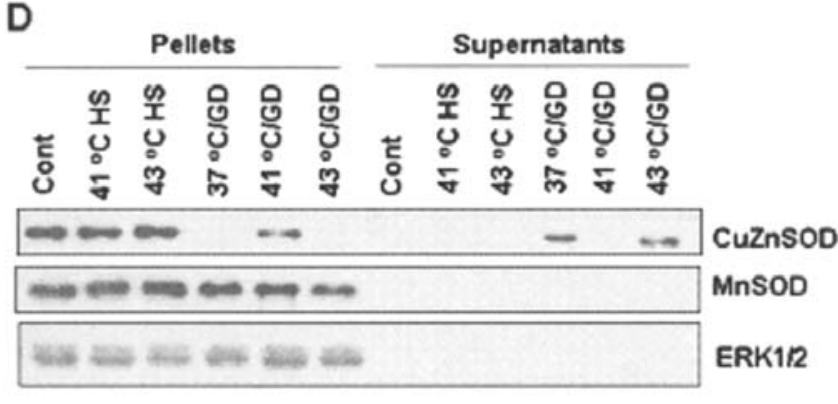

E
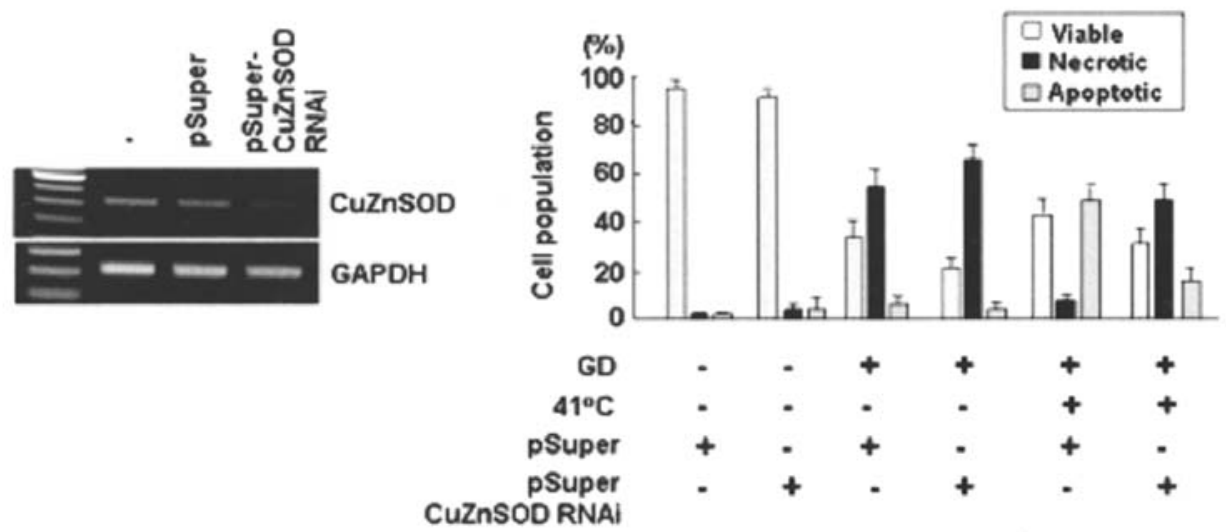

Figure 2. Mild heat shock suppresses the GD-induced ROS production and CuZnSOD release. (A) A549 cells were exposed to heat shock at $41^{\circ} \mathrm{C}$ or $43^{\circ} \mathrm{C}$ for $2.5 \mathrm{~h}$ and exposed to the GD medium for the indicated times. The cells were incubated with DCFH-DA and $\mathrm{HE}$, and intracellular $\mathrm{H}_{2} \mathrm{O}_{2}$ and $\mathrm{O}_{2}$ were determined using a fluorescence microscope. (B and C) A549 cells were exposed to heat shock at $41^{\circ} \mathrm{C}$ or $43^{\circ} \mathrm{C}$ for $2.5 \mathrm{~h}$ and exposed to $\mathrm{GD}$ medium at $37^{\circ} \mathrm{C}$ for the indicated times. The cellular proteins were analyzed by SDS-PAGE and Western blotting with antibodies to CuZnSOD, MnSOD and catalase (B, upper panel). The activity assay for MnSOD, CuZnSOD and catalase was carried out according to Materials and methods (B, lower panel). Total RNA's were prepared from cells for RT-PCR analysis and the first-strand cDNA's were then amplified with primers for CuZnSOD and 3 -actin (C). (D) A549 cells were incubated at $37^{\circ} \mathrm{C}$ or exposed to heat shock at $41^{\circ} \mathrm{C}$ or $43^{\circ} \mathrm{C}$ for $2.5 \mathrm{~h}$ and exposed to GD medium for $18 \mathrm{~h}$. Both the medium bathing the cells (supernatants) and the cells (pellets) were prepared according to Materials and methods, which included analysis by SDS-PAGE and Western blotting with antibodies to CuZnSOD, MnSOD and ERK1/2.

In contrast to general concepts which state that necrotic cell death causes the release of most cellular proteins due to cell membrane rupture, a restricted set of cellular proteins including HMGB1 (Fig. 1C), CuZnSOD (Figs. 2B and D and $3 \mathrm{~A}$ and $\mathrm{B}$ ) and $\mathrm{LDH}$ (Fig. 3B) was selectively released during GD-induced necrotic cell death: although intracellular levels of most, but not all, proteins [including $\alpha$-actin, $\alpha$ tubulin, $\beta$-tubulin (Fig. 3A), p53, caspase-3, and caspase-9 (data not shown)] were decreased during necrosis, they were not detected in the culture medium (Fig. 3A) but formed insoluble aggregate in the cytosol (data not shown). Thus, GD-induced CuZnSOD release appeared to occur in a specific fashion which may accelerate GD-induced necrotic cell death.

We examined whether inhibition of CuZnSOD release is essential for mild heat shock-induced cell death mode 


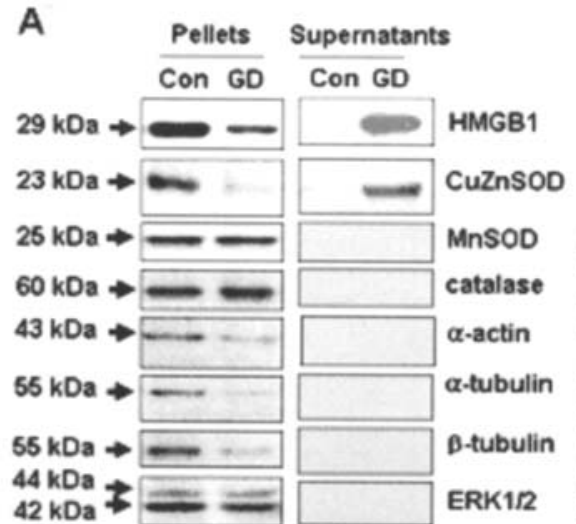

C

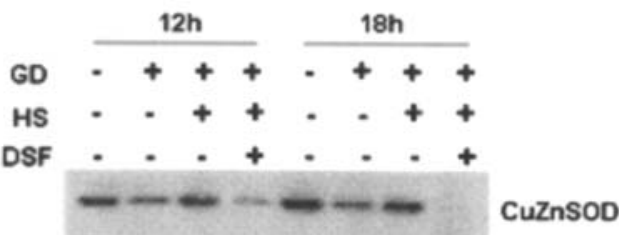

CuZnSOD Fold: $1 \quad 0.43 \quad 0.98 \quad 0.21 \quad 1 \quad 0.37 \quad 0.87 \quad 0.01$

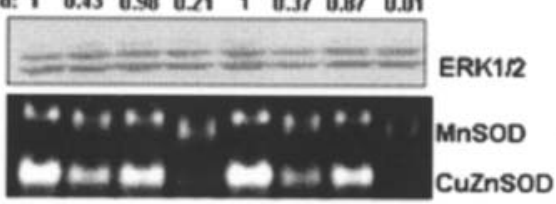

B $\quad 6 \mathrm{~h} \quad 9 \mathrm{~h} \quad 12 \mathrm{~h} \quad 18 \mathrm{~h}$

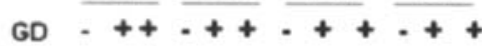

$41^{\circ} \mathrm{CHS} \ldots+\ldots+\ldots+\ldots+$

Pellets $-\infty-\infty-\infty-\cdots$ Cuznsod

Supernatants $\quad-\quad-\quad$ CuZnsod

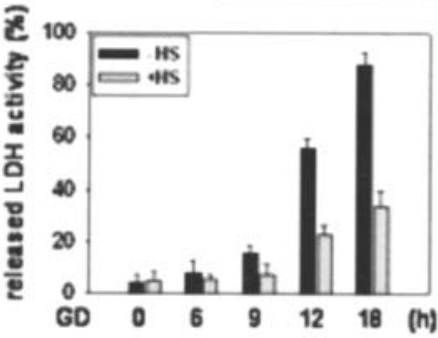

D

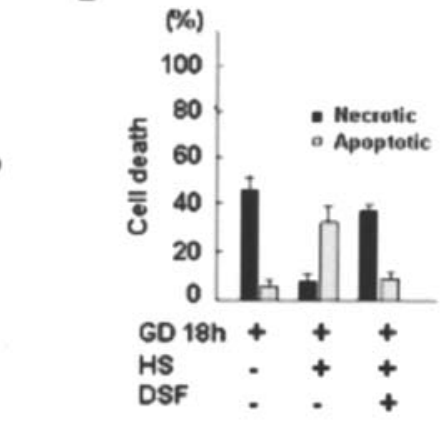

E

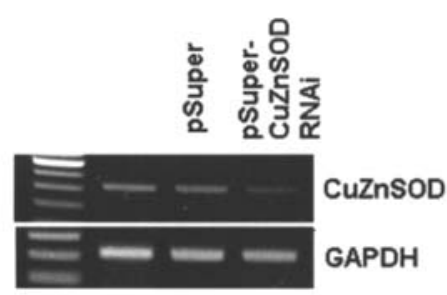

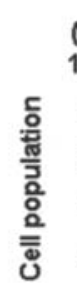

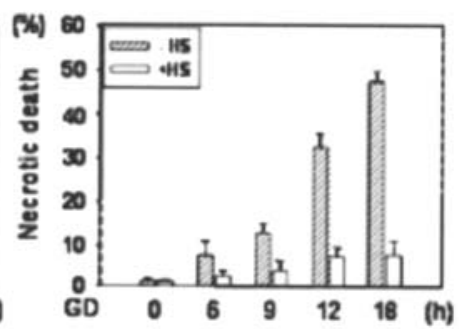

CuZnSOD Fold: $1 \quad 0.35 \quad 0.78 \quad 0.09 \quad 1 \quad 0.33 \quad 0.670 .01$

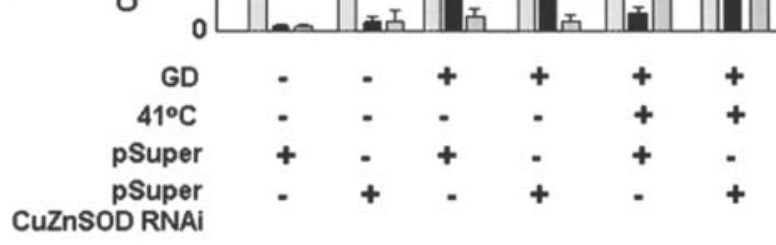

Figure 3. The mild heat shock-induced cell death mode switch is mediated by the suppression of GD-induced CuZnSOD release. (A) A549 cells were cultured in GD medium for $12 \mathrm{~h}$ and both mediums bathing the cells (supernatants). The cells (pellets) were prepared as described in Materials and methods and analyzed by Western blotting using antibodies to HMGB1, CuZnSOD, MnSOD, catalase, actin, $\alpha$-tubulin, $\alpha$-tubulin and ERK1/2. (B) A549 cells were exposed to heat shock at $41^{\circ} \mathrm{C}$ for $2.5 \mathrm{~h}$ and incubated in the GD medium for the indicated times. The protein levels of CuZnSOD and released LDH enzyme into medium were analyzed by Western blotting (upper panel) or LDH activity assay (lower left panel). The cells were stained with HO/PI and observed under a fluorescence microscope. Necrotic cells were scored. Data are the means \pm SEM from three independent experiments (lower right panel). (C) A549 cells were pre-treated with DSF $(1 \mu \mathrm{M})$ and exposed to heat shock at $41^{\circ} \mathrm{C}$ for $2.5 \mathrm{~h}$ and exposed to the GD medium for 12 or $18 \mathrm{~h}$. The cellular proteins were analyzed by SDS-PAGE and Western blotting with antibodies to CuZnSOD and ERK1/2 (C, upper panel). The enzyme activity assay for MnSOD and CuZnSOD was carried out as described in Materials and methods section (C, lower panel). (D) The cells were stained with HO/PI and observed under a fluorescence microscope. Apoptotic and necrotic cells were scored. Data are the means \pm SEM from three independent experiments. (E) A549 cells were transfected with pSUPER-control shRNA, pSUPER-CuZnSOD shRNA, and exposed to heat shock at $41^{\circ} \mathrm{C}$ for $2.5 \mathrm{~h}$ and exposed to GD medium for $18 \mathrm{~h}$. CuZnSOD knock-down by shRNA was analyzed by RT-PCR (left panel). The cells were stained with HO/PI and observed under a fluorescence microscope. Apoptotic and necrotic cells were scored (right panel). The cell type results (500-800 cells in each group) are the means \pm SEM from three independent experiments.

switch. Disulfiram (1 $\mu \mathrm{M})$, a CuZnSOD inhibitor (44), prevented the cell death mode switch effects of mild heat shock, indicating a critical roles of CuZnSOD in mild heat shock-mediated cell death mode switch (Fig. 3C). Disulfiram markedly suppressed mild heat shock-induced prevention of CuZnSOD release (Fig. 3D). Its inhibitory effects on CuZnSOD activity may result in an increase in ROS levels, which accelerates CuZnSOD release. To confirm the role(s) of CuZnSOD in mild heat shock-induced cell death mode switch, pSUPER-shCuZnSOD vector was transiently tran- 
A

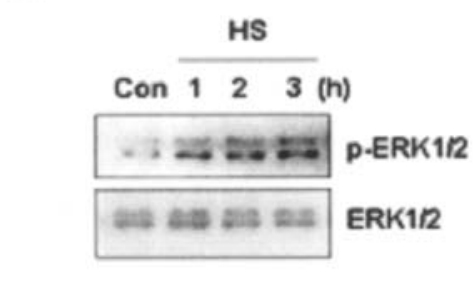

B

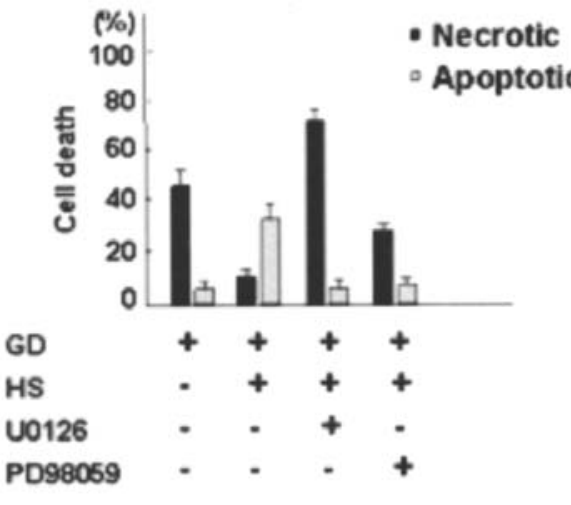

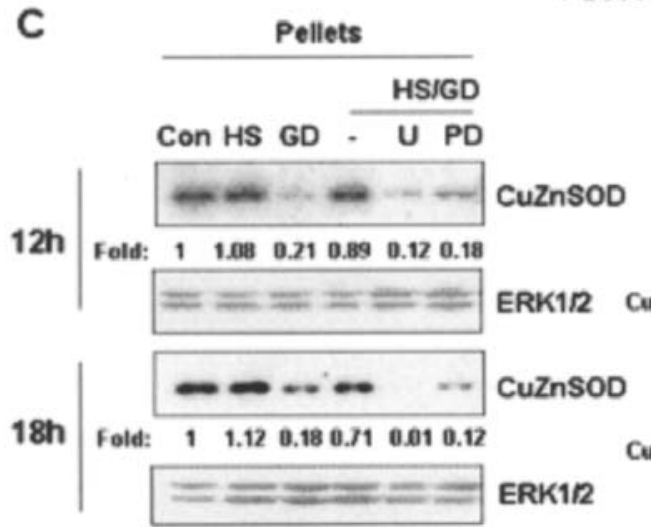

Pellets Supernatants
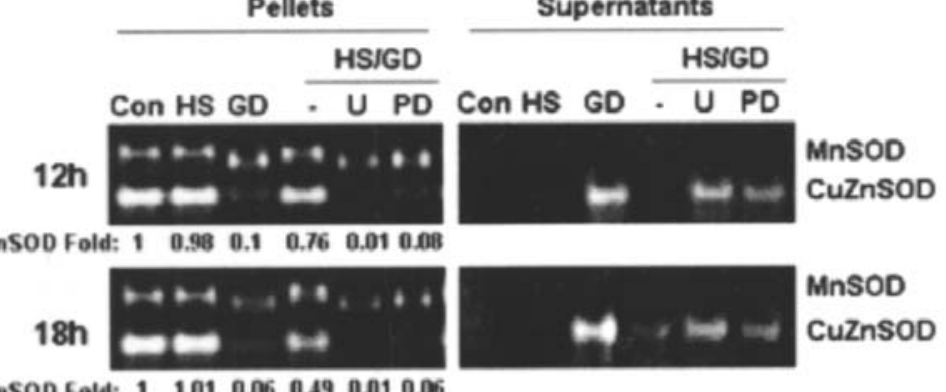

CuZnSOD Fold: $1 \quad 1.010 .06 \quad 0.490 .010 .06$

Figure 4. The ERK1/2 pathway is involved in mild heat shock-induced cell death mode switch and suppression of CuZnSOD release. (A) A549 cells were exposed to heat shock at $41^{\circ} \mathrm{C}$ for the indicated times and the resulting cell lysates were analyzed by Western blotting with antibodies to phospho-ERK $1 / 2$ and ERK1/2. (B) A549 cells were pre-treated with $10 \mu \mathrm{M}$ U0126 or $30 \mu \mathrm{M}$ PD98059 for $1 \mathrm{~h}$ and exposed to heat shock at $41^{\circ} \mathrm{C}$ for $2.5 \mathrm{~h}$ and then exposed to GD medium in the presence of U0126 or PD98059 at $37^{\circ} \mathrm{C}$ for $18 \mathrm{~h}$. The cells were stained with HO/PI and apoptotic and necrotic cells were scored. In these analyses, 500-800 cells of each group were counted. Data are expressed as the means \pm SEM from three independent experiments. (C) A549 cells were pretreated with $\mathrm{U} 0126(\mathrm{U}, 10 \mu \mathrm{M})$ or PD98059 (PD, $30 \mu \mathrm{M})$ for $1 \mathrm{~h}$ and exposed to heat shock at $41^{\circ} \mathrm{C}$ for $2.5 \mathrm{~h}$ and then treated with GD medium for the indicated times and with both mediums bathing the cells (supernatants) and the cells (pellets) were prepared as described in Materials and methods. The proteins were analyzed by SDS-PAGE and Western blotting using antibodies of CuZnSOD and ERK1/2 (left panel). The enzyme activity assay for MnSOD and CuZnSOD was carried out according to Materials and methods (right panel).

sfected in A549 cells and its effect on mild heat shockinduced cell death mode switch was analysed. The efficiency of CuZnSOD interference was observed in transfected cells with very low levels $(<10 \%$ over the corresponding control) of CuZnSOD mRNA (Fig. 3E). Mild heat shock-induced cell death mode switch was prevented in A549 cells with silenced CuZnSOD expression (Fig. 3E).

ERK1/2 is involved in mild heat shock-induced necrosisto-apoptosis switch and prevention of GD-induced $\mathrm{CuZnSOD}$ release. Next, we investigated the signal pathways by which mild heat shock induces necrosis to apoptosis switch and prevents GD-induced CuZnSOD release. As shown previously (10), pre-treatment of mild heat shock activated ERK1/2 (Fig. 4A). In addition, inhibition of MEK by U0126 (a MEK1/2 inhibitor) and PD98059 (a MEK1 inhibitor) blocked the cell death mode switch effects of mild heat shock and reversed the cell death mode to necrosis (Fig. 4B), indicating the crucial role(s) of ERK1/2 in mild heat shockmediated necrosis-to-apoptosis swtch. The MEK1/2 inhibitors suppressed mild heat shock-mediated inhibition of CuZnSOD release, as revealed by Western blotting and enzyme activity assay (Fig. 4C). Thus, mild heat shock appeared to switch GD-induced necrotic death to apoptosis in A549 cells through the ERK1/2 pathway that could suppress GD-induced CuZnSOD release and ROS production.

\section{Discussion}

Both our previous and present studies revealed that GDinduced necrosis in A549 cells depends on cytotoxic ROS including $\mathrm{O}_{2}$ and $\mathrm{H}_{2} \mathrm{O}_{2}$. Here we show that mild heat shock $\left(41^{\circ} \mathrm{C}\right.$ for $\left.2.5 \mathrm{~h}\right)$ markedly prevented GD-induced necrosis and switched the cell death mode to apoptosis that depends on caspase-9 (activated via mitochondrial death pathway) and caspase-3 (Fig. 1); in contrast, harsh heat shock $\left(43^{\circ} \mathrm{C}\right.$ for $2.5 \mathrm{~h}$ ) slightly enhanced GD-induced necrosis. We also show that pre-treatment of mild, but not harsh, heat shock significantly suppressed GD-induced CuZnSOD release and ROS production (Fig. 2). Necrotic cell death has been suggested to cause the release of most cellular proteins due to cell membrane rupture. However, although the levels of several proteins including $\alpha$-actin, $\alpha$-tubulin, $\beta$-tubulin (Fig. 3A), p53, caspase-3, and caspase-9 (data not shown) 
were decreased with GD, these proteins were not detected in the culture medium and forms insoluble aggregate (data not shown). In fact, a restricted set of cellular proteins including CuZnSOD, HMGB1 and LDH was selectively released during GD-induced necrotic cell death. Thus, GD-induced $\mathrm{CuZnSOD}$ release into the extracellular space appeared to occur in a specific fashion which may accelerate GD-induced necrotic cell death. Disulfiram (Fig. 3C and D) or RNA interference of CuZnSOD (Fig. 3E) prevented the cell death mode switch effects of mild heat shock, indicating that GD-induced CuZnSOD release is a step for GD-induced necrosis (Fig. 3). Since CuZnSOD possesses anti-necrotic activities, its knockdown may allow necrotic cell death thereby preventing apoptotic cell death. The molecular mechanism for selective release and escape from protein aggregation of $\mathrm{CuZnSOD}$ remains to be elucidated. CuZnSOD may detoxify $\mathrm{O}_{2}$ which is produced from the electron transport chain in mitochondria and can be released to cytosol possibly through Complex III (45). Accumulating data have suggested that CuZnSOD have been implicated as tumor suppressors and as metastasis suppressors in many tumor cell lines $(46,47)$. For instance, the malignant phenotype and tumor incidences are suppressed when CuZnSOD is stably overexpressed in cancer cells $(46,47)$. A variety of cancer cells have reduced levels of antioxidant enzymes, when compared with their normal counterpart $(46,47)$, thereby explaining the impairment of the antioxidant system, rendering cells vulnerable to the damaging effects of ROS, including DNA damage and protein modifications which contribute to carcinogenesis. Therefore, GD may also contribute to tumor growth and aggressiveness through releasing the tumor suppressor $\mathrm{CuZnSOD}$.

We further demonstrate that the mild heat shock-induced cell death mode switch is mediated by ERK/12 (Fig. 4). Previously, we demonstrated that PKC-dependent ERK1/2 activation switched GD-induced necrosis to apoptosis through inhibition of ROS production, may occur by the regulation of superoxide dismutases (41). In addition, the ERK1/2 pathway is responsible for mild heat shock induction of cyclin D (16). Recently, the MEK1 inhibitors U0126 and PD184161 have been shown to aggravate necrotic death of glucose-deprived cells by inhibiting ATP synthase function, which in turn, indicates that ERK1/2 acts as as an anti-necrotic pathway in GD-induced cell death (48). Out results demonstrated that the mild heat shock-ERK1/2 signal pathway may exert the cell death mode switch activities through preventing mitochondrial ROS production by suppressing the molecular mechanism responsible for the selective release of CuZnSOD.

Heat shock is documented to prevent or promote cell viability and proliferation depending on the strength and duration of applied heat stress as well as biological factors, including, the types of analyzed cell lines. Severe heat shock acts as a proteotoxic stress which causes protein denaturation in cells and exerts a variety of anti-proliferative effects in mammalian cells (7-13), whereas heat shock promotes cell proliferation. Moreover, a mild heat shock response is thought to be controlled by a unique signal cascade which involves the Ras/Rac1 and ERK1/2 signal pathway which is possibly activated by the thermal changes in the fluidity of membrane lipids (18-20). Severe shock has been shown to induce ROS such as $\mathrm{O}_{2} \cdot \mathrm{H}_{2} \mathrm{O}_{2}$, and $\mathrm{OH}^{-}(12,21-24)$, and heat-mediated oxidative stress is involved in heat shock-induced cytotoxicity as well as cell death (12). However, our results showed that mild heat shock could reduce cellular oxidative stress by regulating cellular CuZnSOD distribution.

To the best of our knowledge, this is the first study demonstrating the possibilty of mild heat shock preventing necrotic cell death and switching from the cell death mode to apoptosis, while severe heat shock accelerates necrotic cell death. The effects of heat stress on cell death appeared to depend on the strength and the duration of applied heat stress $(20,49)$. It is very difficult to define the terms 'mild' and 'severe', since the effects of heat stress are determined by both heat temperature and exposure time: each increase in temperature by $1^{\circ} \mathrm{C}$ corresponds to halving the time required for the same extent of the heat shock response $(20,49)$. Furthermore, heat shock sensitivity varies depending on biological factors including cell types, tissue origin, developmental stage, and cell cycle phase of the cell line analyzed as well as the cellular events measured. Thus, the criteria for grading heat stress should be considered in both arithmetic and biological aspects $(20,49)$. These findings may have some biological relevance: i) since necrosis causes inflammation through HMGB1 (33-38), mild heat shock may prevent an inflammatory response, whereas harsh heat shock accelerates the response; ii) hyperthermia has the potential for antineoplastic treatment modality when combined with radiation or chemotherapy (1-3). Clinical trials have shown that when therapeutic hyperthermia is used as an adjuvant with ionizing radiation, significant improvement in local-regional control can be achieved (1-3). Although hyperthermic improvement in clinical outcome is suggested to be linked to its ability to induce cell cycle arrest and apoptosis, and to activate the immune system and to cause increases in blood flow and tumor oxygenation, the mechanism behind this is still unclear. The mild heat shock-induced cell death mode switch from tumor promoting nectosis to tumor suppressive apoptosis may explain one of molecular mechanisms of hyperthermia acting as a potential anti-neoplastic treatment modality when combined with radiation or chemotherapy; iii) furthermore, our results also give an explanation of the molecular mechanism for fever of unknown origin (FUO). Tumors including lymphoma, renal cell carcinoma, hepatocellular carcinoma, and colon carcinoma are occasionally accompanied by FUO characterized by fever higher than $38.3^{\circ} \mathrm{C}$ for more than 3 weeks and no established diagnosis, despite 1 week of intensive evaluation (50-52). Although FUO's are suspected to be caused by necrosis resulting from the rapid growth of tumor and by neoplasm-induced pyrogens, the pathophysiology of neoplastic fever is not well understood (50-52). Our results demonstrate that severe heat shock accelerates GD-induced necrosis and may explain the harmful effects of FUO in tumor development.

\section{Acknowledgments}

This study was supported by grants from the Ministry of Science and Technology, Korea, and the Korea Science and Engineering Foundation through the Research Center for Resistant Cells (R13-2003-009). 


\section{References}

1. Van der Zee J, González González D, van Rhoon GC, van Dijk JD, van Putten WL and Hart AA: Comparison of radiotherapy alone with radiotherapy plus hyperthermia in locally advanced pelvic tumors: a prospective, randomised, multicentre trial. Lancet 355: 1119-1125, 2000 .

2. Corry PM and Armour EP: The heat shock response: role in radiation biology and cancer therapy. Int $\mathbf{J}$ Hyperthermia 21: 769-778, 2005.

3. Sekhar KR, Sonar VN, Muthusamy V, Sasi S, Laszlo A, Sawani J, Horikoshi N, Higashikubo R, Bristow RG, Borrelli MJ, Crooks PA, Lepock JR, Roti Roti JL and Freeman ML: Novel chemical enhancers of heat shock increase thermal radiosensitization through a mitotic catastrophe pathway. Cancer Res 67: 695-701, 2007.

4. Pirkkala L, Nykanen P and Sistonen L: Roles of the heat shock transcription factors in regulation of the heat shock response and beyond. FASEB J 15: 1118-1131, 2001.

5. Takayama S, Reed JC and Homma S: Heat-shock proteins as regulators of apoptosis. Oncogene 22: 9041-9047, 2003.

6. Mehlen P, Kretz-Remy C, Préville X and Arrigo AP: Human hsp27, Drosophila hsp 27 and human alphaB-crystallin expression-mediated increase in glutathione is essential for the protective activity of these proteins against TNFalpha-induced cell death. EMBO J 15: 2695-2706, 1999.

7. Kuhl NM and Rensing L: Heat shock effects on cell cycle progression. Cell Mol Life Sci 57: 450-463, 2000.

8. Trotter EW, Berenfeld L, Krause SA, Petsko GA and Gray JV: Protein misfolding and temperature up-shift cause G1 arrest via a common mechanism dependent on heat shock factor in Saccharomyces cerevisae. Proc Natl Acad Sci USA 98: 7313-7318, 2001

9. Ohnishi T, Wang X, Ohnishi K, Matsumoto H and Takahashi A: P53-dependent induction of WAF1 by heat treatment in human glioblastoma cells. J Biol Chem 271: 14510-14513, 1996.

10. Nitta M, Okamura H, Aizawa S and Yamaizumi M: Heat shock induces transient p53-dependent cell cycle arrest at G1/S. Oncogene 15: 561-568, 1997.

11. Kondo T, Matsuda T, Tashima M, Umehara H, Domae N, Yokoyama K, Uchiyama T and Okazaki T: Suppression of heat shock protein-70 by ceramide in heat shock-induced HL-60 cell apoptosis. J Biol Chem 275: 8872-8879, 2000.

12. Katschinski DM, Boos K, Schindler SG and Fandrey J: Pivotal role of reactive oxygen species as intracellular mediators of hyperthermia-induced apoptosis. J Biol Chem 275: 21094-21098, 2000.

13. Milleron RS and Bratton SB: Heat shock induces apoptosis independently of any known initiator caspase-activating complex. J Biol Chem 281: 16991-17000, 2006.

14. Hanson DF: Fever and the immune response. The effects of physiological temperatures on primary murine splenic T-cell responses in vitro. J Immunol 151: 436-448, 1993.

15. Shui $C$ and Scutt A: Mild heat shock induces proliferation, alkaline phosphatase activity, and mineralization in human bone marrow stromal cells and MG-63 cells in vitro. J Bone Miner Res 16: 731-741, 2001.

16. Han SI, Oh SY, Jeon WJ, Kim WJ, Lee JH and Kang HS: Mild heat shock induces cycin D1 synthesis through multiple Ras signal pathways. FEBS Lett 515: 141-145, 2002.

17. Han SI, Oh SY, Woo SH, Kim KH, Kim JH, Kim HD and Kang HS: Implication of a small GTPase Rac1 in the activation of c-jun N-terminal kinase and heat shock factor in response of heat shock. J Biol Chem 276: 1889-1895, 2001.

18. Vigh L, Maresca B and Harwood JL: Does the membrane's physical state control the expression of heat shock and other genes? Trends Biochem Sci 23: 369-374, 1998.

19. Torok Z, Tsvetkova NM, Balogh G, Horvath I, Nagy E, Penzes Z, Hargitai J, Bensaude O, Csermely P, Crowe JH, Maresca B and Vigh L: Heat shock protein coinducers with no effect on protein denaturation specifically modulate the membrane lipid phase. Proc Natl Acad Sci USA 100: 3131-3136, 2003.

20. Park HG, Han SI, Oh SY and Kang HS: Cellular responses to mild heat stress. Cell Mol Life Sci 62: 10-23, 2005.

21. Davidson JF and Schiestl RH: Mitochondrial respiratory electron carriers are involved in oxidative stress during heat stress in Saccharomyces cerevisiae. Mol Cell Biol 21: 8483-8489, 2001.

22. Flanagan SW, Moseley PL and Buettner GR: Increased flux of free radicals in cells subjected to hyperthermia: detection by electron paramagnetic resonance spin trapping. FEBS Lett 431: 285-286, 1998.
23. Gorman AM, Heavey B, Creagh E, Cotter TG and Samali A: Antioxidant-mediated inhibition of the heat shock response leads to apoptosis. FEBS Lett 445: 98-102, 1999.

24. Sreedhar AS, Pardhasaradhi BV, Khar A and Srinivas UK: A cross talk between cellular signalling and cellular redox state during heatinduced apoptosis in a rat histiocytoma. Free Radic Biol Med 32: 221-227, 2002.

25. Mates JM and Sanchez-Jimenez F: Antioxidant enzymes and their implications in pathophysiologic processes. Front Biosci 4: D339-D345, 1999.

26. Martindale JL and Holbroo NJ: Cellular response to oxidative stress: signaling for suicide and survival. J Cell Physiol 192: $1-15,2002$.

27. Hengartner MO: The biochemistry of apoptosis. Nature 407: 770-776, 2000.

28. Martinou JC and Green DR: Breaking the mitochondrial barrier. Nat Rev Mol Cell Biol 2: 63-67, 2001.

29. Sperandio S, De Belle I and Bredesen DE: An alternative, non-apoptotic form of programmed cell death. Proc Natl Acad Sci USA 97: 14376-14381, 2000.

30. Zong WX and Thompson CB: Necrotic death as a cell fate. Genes Dev 20: 1-15, 2006.

31. Syntichaki $\mathrm{P}$ and Tavernarakis $\mathrm{N}$ : Death by necrosis. Uncontrollable catastrophe, or is there order behind the chaos? EMBO Rep 3: 604-609, 2002.

32. Chiarugi A: 'Simple but not simpler': toward a unified picture of energy requirements in cell death. FASEB J 19: 1783-1788, 2005.

33. Vakkila $\mathrm{J}$ and Lotze MT: Inflammation and necrosis promote tumour growth. Nat Rev Immunol 4: 641-648, 2004.

34. Scaffidi P, Misteli $\mathrm{T}$ and Bianchi ME: Release of chromatin protein HMGB1 by necrotic cells triggers inflammation. Nature 418: 191-195, 2002.

35. Taguchi A, Blood DC, Del Toro G, Canet A, Lee DC, Qu W, Tanji N, Lu Y, Lalla E, Fu C, Hofmann MA, Kislinger T, Ingram M, Lu A, Tanaka H, Hori O, Ogawa S, Stern DM and Schmidt AM: Blockade of RAGE-amphoterin signalling suppresses tumour growth and metastases. Nature 405: 354-360, 2000.

36. Schlueter C, Weber H, Meyer B, Rogalla P, Roser K, Hauke S and Bullerdiek J: Angiogenetic signaling through hypoxia: HMGB1: an angiogenetic switch molecule. Am J Pathol 166: 1259-1263, 2005 .

37. Degenhardt K, Mathew R, Beaudoin B, Bray K, Anderson D, Chen G, Mukherjee C, Shi Y, Gelinas C, Fan Y, Nelson DA, Jin $\mathrm{S}$ and White E: Autophagy promotes tumor cell survival and restricts necrosis, inflammation, and tumorigenesis. Cancer Cell 10: 51-64, 2006.

38. Lotze MT and Tracey KJ: High-mobility group box 1 protein (HMGB1): nuclear weapon in the immune arsenal. Nat Rev Immunol 5: 331-342, 2005.

39. Gatenby RA and Gillies RJ: Why do cancers have high aerobic glycolysis? Nat Rev Cancer 4: 891-899, 2004

40. Beasley NJ, Wykoff CC, Watson PH, Leek R, Turley H, Gatter K, Pastorek J, Cox GJ, Ratcliffe P and Harris AL: Carbonic anhydrase IX, an endogenous hypoxia marker, expression in head and neck squamous cell carcinoma and its relationship to hypoxia, necrosis and microvessel density. Cancer Res 61: 5262-5267, 2001

41. Kim CH, Han SI, Lee SY, Youk HS, Moon JY, Duong HQ, Park MJ, Joo YM, Park HG, Kim YJ, Yoo MA, Lim SC and Kang HS: Protein kinase C-ERK1/2 signal pathway switches glucose depletion-induced necrosis to apoptosis by regulating superoxide dismutases and suppressing reactive oxygen species production in A549 lung cancer cells. J Cell Phyiol 211: 371-385, 2007.

42. Lim S-C, Choi JE, Kim CH, Duong H-Q, Jeong G-A, Kang HS and Han SI: Ethyl pyruvate induces necrosis-to-apoptosis switch and inhibits high mobility group box protein 1 release in A549 lung adenocarcinoma cells. Int J Mol Med 20: 187-192, 2007.

43. Ahmad IM, Aykin-Burns N, Sim JE, Walsh JE, Higashikubo R, Buettner GR, Venkataraman S, Mackey MA, Flanagan SW, Oberley LW and Spitz DR: Mitochondrial $\mathrm{O}_{2}{ }^{*}-$ and $\mathrm{H}_{2} \mathrm{O}_{2}$ mediate glucose deprivation-induced stress in human cancer cells. J Biol Chem 280: 4254-4263, 2005.

44. Marikovsky M, Ziv V, Nevo N, Harris-Cerruti C and Mahler O: $\mathrm{Cu} / \mathrm{Zn}$ superoxide dismutase plays important role in immune response. J Immunol 170: 2993-3001, 2003. 
45. Muller FL, Liu Y and van Remmen H: Complex III releases superoxide to both sides of the inner mitochondrial membrane. J Biol Chem 279: 49064-49073, 2004.

46. Elchuri S, Oberley TD, Qi W, Eisenstein RS, Jackson Roberts L, van Remmen H, Epstein CJ and Huang TT: CuZnSOD deficiency leads to persistent and widespread oxidative damage and hepatocarcinogenesis later in life. Oncogene 24: 367-380, 2005.

47. Weydert CJ, Waugh TA, Ritchie JM, Iyer KS, Smith JL, Li L, Spitz DR and Oberley LW: Overexpression of manganese or copper-zinc superoxide dismutase inhibits breast cancer growth. Free Radic Biol Med 41: 226-237, 2006.

48. Yung HW, Wyttenbach A and Tolkovsky AM: Aggravation of necrotic death of glucose-deprived cells by the MEK1 inhibitors U0126 and PD184161 through depletion of ATP. Biochem Pharmacol 15: 351-360, 2004
49. Dewey WC: Failla memorial lecture. The search for critical cellular targets damaged by heat. Radiat Res 120: 191-204, 1989.

50. Arnow PM and Flaherty JP: Fever of unknown origin. Lancet 350: $575-580,1997$

51. Tal S, Guller V, Gurevich A and Levi S: Fever of unknown origin in the elderly. J Intern Med 252: 295-304, 2002.

52. Agmon-Levin N, Ziv-Sokolovsky N, Shull P and Sthoeger ZM: Carcinoma of colon presenting as fever of unknown origin. Am J Med Sci 329: 322-326, 2005. 